\title{
Mental health of refugee children: comparative study
}

\author{
Mina Fazel, Alan Stein
}

Section of Child and Adolescent Psychiatry, University Department of Psychiatry,

Warneford Warneford Hospital, Oxford OX3 7JX

Mina Fazel clinical lecturer Alan Stein professor Correspondence to: M Fazel minafazel@ psych.ox.ac.uk

BMJ 2003;327:134
In 2002, over 110000 people entered Britain to seek asylum-a 250\% increase in five years. ${ }^{1}$ Children, who comprise at least a quarter of asylum seekers, are exposed to numerous risk factors for psychological disturbance, including exposure to violence, forced displacement, and multiple losses. ${ }^{2}$ The rates of mental health problems in refugee children are uncertain, but the few studies that have been done suggest that refugee children incur significant morbidity. ${ }^{2}$

We examined the rates of psychological disturbance in a sample of UK children who were refugees and compared them with a group of children who were from an ethnic minority but were not refugees and a group of indigenous white children.

\section{Participants, methods, and results}

The six schools in Oxford with the largest number of refugee children agreed to participate. At these schools, all 115 children who were refugees or seeking asylum were identified, and we wrote to the parents or guardians of each. We asked permission, in English and the parent's native language, for the child's class teacher to complete a questionnaire on their child's psychosocial adjustment. One parent refused and the teachers of 13 children did not return questionnaires (without providing reasons) leaving 101 refugee children in the study. We individually matched refugee children for age and sex with the next ethnic minority and the next white child in the alphabetical class list. If a parent refused $(n=8)$ the next appropriate child on the register was recruited.

The sample comprised 303 children. In each group were 61 boys and 40 girls; 32 children were aged 5-9, 35 were aged 10-13, and 34 were aged 14-18 years. Regions of origin for the refugee children included the Balkans (48), Kashmir (16), and Afghanistan (10) and for the ethnic minority children Pakistan (64) and Bangladesh (28).

Teachers assessed the children's emotional and behavioural adjustment using the "strengths and difficulties questionnaire" (SDQ), which is well validated and widely used. ${ }^{3}$ The questionnaire has 25 items, which generate five subscales-emotional symptoms, peer problems, hyperactivity, conduct

Scores for refugee children, children from ethnic minorities, and indigenous white children, matched for age and sex, from the strengths and difficulties questionnaire

\begin{tabular}{|c|c|c|c|c|c|}
\hline \multirow[b]{2}{*}{$\begin{array}{l}\text { Subscale of the strengths } \\
\text { and difficulties } \\
\text { questionnaire (SDQ) }\end{array}$} & \multicolumn{3}{|c|}{ Median SDQ score (range) } & \multicolumn{2}{|c|}{ Wilcoxon's rank sum test } \\
\hline & Refugee & $\begin{array}{l}\text { Ethnic } \\
\text { minority }\end{array}$ & $\begin{array}{l}\text { Indigenous } \\
\text { white }\end{array}$ & $\begin{array}{c}\text { Refugee } v \\
\text { ethnic minority }\end{array}$ & $\begin{array}{c}\text { Refugee } v \\
\text { indigenous } \\
\text { white }\end{array}$ \\
\hline Total & $9(0-28)$ & $7(0-21)$ & $6(0-31)$ & $3.0^{* *}$ & $2.9^{* *}$ \\
\hline Emotional & $2(0-10)$ & $1(0-9)$ & $1(0-8)$ & $4.3^{* \star \star}$ & $3.2^{\star \star}$ \\
\hline Peer & $2(0-8)$ & $1(0-8)$ & $1(0-9)$ & 1.8 & $2.9^{* *}$ \\
\hline Hyperactivity & $4(0-10)$ & $3(0-10)$ & $3(0-10)$ & 1.6 & $2.1^{*}$ \\
\hline Conduct disorder & $1(0-8)$ & $1(0-8)$ & $0(0-9)$ & 0.5 & 0.4 \\
\hline Prosocial & $6(0-10)$ & $6(0-10)$ & $7(0-10)$ & 0.4 & $2.3^{*}$ \\
\hline
\end{tabular}

disorder, and prosocial behaviour-and a separate impact score. We did two sets of analyses comparing the refugee children to each of the control groups. Firstly, psychiatric cases were compared with noncases using a definition of "caseness" by combining raised symptoms $(\mathrm{SDQ} \geqslant 14)$ and impact scores $(\geqslant 2) .{ }^{4}$ Comparisons showed significant differences with $27 \%$ (95\% confidence interval $19 \%$ to $36 \%$ ) of refugee children, $9 \%(5 \%$ to $16 \%)$ of children from ethnic minorities, and $15 \%(9-23 \%)$ of white children meeting case criteria. Significantly more refugee children were cases than children from ethnic minorities $(\mathrm{P}<0.01)$ and there was a strong trend for more refugee than white children to be cases $(\mathrm{P}=0.059)$.

Secondly, we compared the groups on total SDQ scores and on each subscale (table). Refugee children scored significantly higher than ethnic minority children on both total $(\mathrm{P}<0.01)$ and emotional $(\mathrm{P}<0.001)$ scores; and refugee children scored higher than white children on total $(\mathrm{P}<0.01)$, emotional $(\mathrm{P}<0.01)$, peer $(\mathrm{P}<0.01)$, and hyperactivity $(\mathrm{P}<0.05)$ scores.

\section{Comment}

More than a quarter of refugee children had significant psychological disturbance-greater than in both control groups and three times the national average. These refugee children show particular difficulties in emotional symptoms.

Limitations of the study are that we did not use parents as informants and did not do diagnostic interviews. As refugee children have access to only limited clinical services, our findings raise considerable concern that refugee children have large unmet mental health needs that need to be tackled. The development of services should include collaboration with schools, primary health care, and community child mental health teams.

We thank D Anne Schmidt for help in the statistical analysis and to Mario Cortina Borja for statistical advice. We thank the teachers who kindly completed questionnaires.

Contributors: MF and AS designed the study and wrote the paper. DAS did the statistical analysis. MF performed the study, assembled the data, and is guarantor.

Funding: MF was funded by a Wellcome research senior house officer grant.

Competing interests: AS's clinical work with refugee children is funded by the charity Action for Children in Conflict.

Ethical approval: Oxfordshire Psychiatric Ethics Committee.

1 Home Office. Asylum statistics: 4th quarter 2002 United Kingdom. London: Immigration, Research and Statistics Service, 2003.

Fazel M, Stein A. The mental health of refugee children. Arch Dis Child 2002;87:366-70

3 Goodman R, Ford T, Simmons H, Gatward R, Meltzer H. Using the strengths and difficulties questionnaire (SDQ) to screen for child psychiatric disorders in a community sample. BrJ Psychiatry 2000;177:534-9.

Goodman R, Ford T, Meltzer H. Mental health problems of children in the community: 18 month follow up. BMJ 2002;321:1496-7.

Meltzer H, Gatward R, Goodman R, Ford T. Mental health of children and adolescents in Great Britain. Stationery Office: London, 2000.

(Accepted 1 May 2003) 